\title{
PRENATAL YOGA TERHADAP TINGKAT KECEMASAN PRIMIGRAVIDA TRIMESTER III
}

\author{
Riza Amalia, Rusmini , Diki Retno Yuliani \\ Poltekkes Kemenkes Semarang \\ Email : rizaamalia12@gmail.com
}

\begin{abstract}
Anxiety in pregnant women often occurs in the third trimester. Anxiety results in prolonged labor, premature birth, LBW (Low Birth Weight). To prevent and reduce anxiety, prenatal yoga as an alternative therapy is given to primigravida pregnant women in the third trimester. The puropose of this study is to find out the influence of prenatal yoga toward anxiety level primigravida in the third trimester in Puskesmas I Kembaran, Banyumas District. This study used quasy experimental with pretest posttest design. The sample in this study are all of primigravida in third trimester, there are 24 pregnant woman in Puskesmas 1 Kembaran. The results showed there were differences in primigravida in third trimester anxiety levels before and after prenatal yoga with $p$ value $=0,000$ ( $p$ $<0.05)$. There is an influence of prenatal yoga on the level of anxiety primigravida in third trimester. There is a change in the mean level of anxiety of 11,3 .
\end{abstract}

Key words : prenatal yoga, pregnant mother anxiousness in third trimester, primigravida

\begin{abstract}
ABSTRAK
Kecemasan ibu hamil sering terjadi pada trimester III. Kecemasan berdampak pada persalinan lama, kelahiran premature, BBLR (Berat Badan Lahir Rendah). Untuk mencegah dan mengurangi kecemasan, maka prenatal yoga sebagai suatu alternatif terapi yang diberikan pada ibu hamil primigravida trimester III. Tujuan penelitian ini yaitu mengetahui pengaruh prenatal yoga terhadap tingkat kecemasan primigravida trimester III di kelas ibu hamil wilayah kerja Puskesmas I Kembaran Kabupaten Banyumas. Penelitian ini menggunakan metode quasy eksperimental dengan pendekatan pretest posttest design. Sampel dalam penelitian ini adalah seluruh ibu primigravida trimester III sejumlah 24 ibu di wilayah kerja Puskesmas $1 \mathrm{Kembaran}$. Hasil penelitian diperoleh ada perbedaan tingkat kecemasan primigravida trimester III sebelum dan sesudah prenatal yoga dengan $p$ value $=0,000(p<0,05)$ dan ada perbedaan kualitas tidur primigravida trimester III sebelum dan sesudah prenatal yoga dengan $p$ value $=0,000$ $(p<0,05)$. Ada pengaruh prenatal yoga terhadap tingkat kecemasan primigravida trimester III. Terdapat perubahan mean tingkat kecemasan sebesar 11,3.
\end{abstract}

Kata kunci: prenatal yoga, kecemasan ibu hamil trimester III, primigravida

\section{Pendahuluan}

Kecemasan ibu hamil sering ditemukan pada trimester ketiga atau disebut periode menunggu dan waspada sebab pada saat itu ibu merasa tidak sabar menunggu kelahiran bayinya. Terkadang ibu merasa khawatir ketika bayinya akan lahir sewaktuwaktu. Sehingga ibu lebih waspada bila timbul tanda dan gejala persalinan. Ibu mulai merasa takut akan rasa sakit dan bahaya fisik yang akan timbul pada waktu melahirkan. Rasa tidak nyaman akibat kehamilan muncul kembali, dan banyak ibu merasa dirinya aneh dan jelek, merasa sedih akan berpisah dari bayinya dan kehilangan perhatian khusus yang diterima selama hamil. Sehingga diperlukan dukungan dari suami, keluarga dan bidan 
(Pusdiknakes, 2003). Pada trimester ketiga ini ibu hamil yang menunggu kelahiran dapat mengalami ketakutan apakah persalinannya akan berjalan dengan lancar ataukah caesar dan kemungkinan dapat menimbulkan tekanan yang dapat mengakibatkan dirinya mengalami kecemasan (Kusmiyati, 2009). Ibu hamil mengalami bentuk perubahan psikis yaitu perubahan emosional, cenderung malas, sensitif, meminta perhatian lebih, perasaan tidak nyaman, depresi, stres, dan mengalami kecemasan (Pieter, 2010).

Kekhawatiran dan kecemasan pada ibu hamil apabila tidak ditangani dengan serius akan membawa dampak dan pengaruh terhadap fisik dan psikis, baik pada ibu maupun janin. Ibu yang mengalami kecemasan dan stres, sinyalnya berjalan melalui HPA (Hipotalamo-Pituitary-Adrenal) yang dapat menyebabkan lepasnya hormon stres antara lain ACTH (Adreno Cortico Tropin Hormone), kortisol, dan katekolamin. Lepasnya hormon - hormon stres tersebut mengakibatkan terjadinya vasokonstriksi sistemik, termasuk diantaranya konstriksi vasa utero plasenta yang menyebabkan gangguan aliran darah di dalam rahim, sehingga transportasi oksigen ke dalam miometrium terganggu dan mengakibatkan lemahnya kontraksi otot rahim. Kejadian tersebut menyebabkan makin lamanya proses persalinan (partus lama) sehingga janin dapat mengalami kegawatan (fetal distres) (Kathyrin, 2012).

Wanita yang menderita stres dan cemas saat kehamilan usia trimester ketiga, akan mengalami peningkatan risiko kelainan bawaan berupa kegagalan penutupan celah palatum, risiko operasi sectio caesarea, persalinan dengan alat, kelahiran prematur, melahirkan bayi dengan berat badan lahir rendah (BBLR) dan dalam jangka panjang berkaitan dengan gangguan perilaku dan emosi anak (Evan, 2002).

Ibu hamil sering memiliki pikiran yang mengganggu, sebagai pengembangan reaksi kecemasan terhadap cerita yang diperolehnya. Adanya pikiran-pikiran seperti melahirkan yang akan selalu diikuti dengan nyeri kemudian akan menyebabkan peningkatan kerja sistem saraf simpatetik. Dalam situasi ini, sistem endokrin, terdiri dari kelenjar-kelenjar, seperti adrenal, tiroid, dan pituitary (pusat pengendalian kelenjar), melepaskan pengeluaran hormon masingmasing ke aliran darah dalam rangka mempersiapkan badan pada situasi darurat. Akibatnya sistem saraf otonom mengaktifkan kelanjar adrenal yang mempengaruhi sistem pada hormon epinefrin. Hormon ini disebut juga hormon adrenalin memberi tenaga pada individu serta mempersiapkan secara fisik dan psikis. Ketika hormon adrenalin dan noradrenalin atau epinefrin dan norepinefrin meningkat, menimbulkan disregulasi biokimia tubuh, sehingga muncul ketegangan fisik pada ibu hamil. Dampak dari proses fisiologis ini dapat timbul seharihari. Ibu hamil menjadi mudah marah atau tersinggung, gelisah, tidak mampu memusatkan perhatian, ragu-ragu bahkan kemungkinan ingin lari dari kenyataan hidup (Kuswandi, 2002)

Penelitian lain menunjukkan bahwa ibu hamil dengan kecemasan yang tinggi ketika hamil akan meningkatkan risiko hipertensi pada kehamilan. Risiko hipertensi dapat berupa terjadinya kejang, bahkan kematian pada ibu dan janin. Jika hal itu dibiarkan terjadi, maka angka mortalitas dan morbiditas pada ibu hamil akan semakin meningkat (Suririnah, 2013)

Kecemasan pada ibu hamil merupakan hal penting yang sering terlupakan. Bidan mempunyai peran yang cukup besar dalam mengatasi masalah tersebut. Bidan harus dapat mengenai gejala kecemasan ibu hamil dan menguranginya dengan memberikan penjelasan mengenali kehamilan, persalinan, kecemasan dan efek kecemasan pada ibu hamil dan janin (Pusdiknakes, 2003).

Yoga prenatal dapat membantu mengurangi stres yang berhubungan dengan kelahiran bayi, mempersiapkan ibu secara fisik dan mental, membantu memperkuat tubuh ibu hamil dan meningkatkan fleksibilitas. Perubahan fisik yang terjadi selama kehamilan akan mempengaruhi sang calon ibu dan membuatnya merasa tidak nyaman, baik secara fisik maupun psikis. Perut yang terus membesar, sesak napas seiring dengan pertumbuhan janin, mood yang tidak menentu, dan kecemasan akan masa persalinan seiring membuat seorang calon ibu merasa tidak percaya diri dan tidak nyaman. Berlatih yoga pada masa ini 
merupakan salah satu self help yang akan mengurangi ketidaknyaman selama masa hamil, membantu proses persalinan, dan bahkan mempersiapkan mental untuk masamasa awal setelah melahirkan dan saat membesarkan anak. Teknik olah napas yang telah dilakukan ibu hamil sedari awal masa kehamilan akan membantu ibu lebih mudah memusatkan pikiran saat bermeditasi yang akan sangat berguna untuk menguatkan mental, mengatasi kecemasan, dan menghemat energi pada detik-detik persalinan kelak (Sindhu, 2014). Gerakan yoga dapat mengurangi tingkat kecemasan ibu hamil dengan meningkatkan sirkulasi darah ke hipotalamus sehingga mempengaruhi sistem saraf parasimpatis dan berdampak pada organ jantung yaitu menormalkan tekanan darah dan pernafasan.

Puskesmas I Kembaran Kabupaten Banyumas, telah memiliki kelas ibu hamil di masing-masing desa. Kelas ibu hamil dilakukan rutin dalam setiap bulannya. Dalam kegiatan kelas ibu hamil, banyak materi yang disampaikan oleh bidan. Selama ini, di kelas ibu hamil baru melaksanakan senam hamil. Sehingga peneliti ingin melakukan penelitian mengenai prenatal yoga. Harapannya prenatal yoga sebagai inovasi dalam asuhan kehamilan yang bisa dilakukan oleh ibu hamil itu sendiri.

\section{Metode Penelitian}

Penelitian ini menggunakan rancangan experimen semu (quasy experiment) dengan design one group pretest posttest. Penelitian ini dilakukan di wilayah kerja Puseksmas I Kembaran. Pengambilan data pada bulan Oktober-November 2018. Sampel dalam penelitian ini yaitu primigravida trimester III sejumlah 24 yang diukur tingkat kecemasan dan kualitas tidur sebelum dan sesudah perlakuan. Kuesioner untuk mengukur tingkat kecemasan menggunakan HARS (Hamilton Anxiety Rating Scale). Perlakuan yang diberikan yaitu prenatal yoga sebanyak 1 kali setiap minggu dalam 4 minggu dengan durasi 60 menit setiap treatment.

Analisis statistik yang digunakan yaitu paired t-test untuk membandingkan tingkat kecemasan sebelum dan sesudah diberikan prenatal yoga.

\section{Hasil dan Pembahasan}

Penelitian prenatal yoga terhadap tingkat kecemasan primigravida trimester III memberikan hasil sebagai berikut.

Tabel 1 Distribusi Frekuensi Tingkat Kecemasan Responden Sebelum Diberikan Perlakuan Prenatal Yoga

\begin{tabular}{lcc}
\hline \multicolumn{1}{c}{ Kecemasan } & $\mathbf{f}$ & $\mathbf{( \% )}$ \\
\hline $\begin{array}{l}\text { Kecemasan } \\
\text { Ringan }\end{array}$ & 5 & $20,8 \%$ \\
$\begin{array}{l}\text { Kecemasan } \\
\begin{array}{l}\text { Sedang } \\
\text { Kecemasan }\end{array}\end{array}$ & 10 & $41,7 \%$ \\
Berat & 9 & $37,5 \%$ \\
\hline Total & 24 & $100 \%$ \\
\hline
\end{tabular}

Data pada tabel 1, kelompok sebelum diberikan perlakuan prenatal yoga menunjukkan dari 24 responden didapatkan $41,7 \%$ mengalami kecemasan sedang dan $37,5 \%$ mengalami kecemasan berat.

Tingkat kecemasan adalah reaksi terhadap ancaman dari rasa sakit maupun dunia luar yang tidak siap ditanggulangi dan berfungsi memperingatkan individu akan adanya bahaya (Field, 2012). Dari data yang didapatkan, menunjukkan bahwa 10 responden dengan tingkat kecemasan sedang. Hal ini tidak diharapkan, karena akan mengganggu kesehatan serta pertumbuhan perkembangan janin. Dan 10 responden tersebut menyatakan faktor yang mempengaruhi dirinya menjadi cemas sangat kompleks, diantaranya yaitu usia, lingkungan dan situasi. Hasil analisis kualitatif menunjukkan adanya beberapa bentuk tingkat kecemasan ibu hamil, antara lain keraguan apakah persalinannya akan berjalan normal, tingkat kecemasan menunggu perkiraan kelahiran. Dampak tingkat kecemasan ini terlihat pada aktivitas sehari-hari seperti merasa tegang selama hamil, lebih sensitif dan mudah tersinggung, serta kesulitan saat memulai tidur. Hal ini sesuai dengan teori bahwa pada saat trimester III, ibu hamil timbul gejolak baru menghadapi persalinan dan perasaan tanggung jawab sebagai ibu (Suririnah, 2013) 
Tabel 2 Distribusi Frekuensi Tingkat Kecemasan Responden Sesudah Diberikan Perlakuan Yoga Prenatal

\begin{tabular}{lcc}
\hline \multicolumn{1}{c}{ Kecemasan } & $\mathbf{f}$ & $\mathbf{( \% )}$ \\
\hline Tidak cemas & 3 & $12,5 \%$ \\
Kecemasan ringan & 15 & $62,5 \%$ \\
Kecemasan sedang & 6 & $25 \%$ \\
\hline Total & 24 & $100 \%$ \\
\hline
\end{tabular}

Data pada tabel 2, tingkat kecemasan sedang menurun $16,7 \%$, sedangkan tingkat kecemasan berat turun $100 \%$.

Yoga prenatal merupakan modifikasi dari yoga klasik yang telah disesuaikan dengan kondisi wanita hamil yang diberikan perlakuan dengan intensitas lembut dan perlahan. Fokus pada trimester III ini adalah untuk menghadapi persalinan. Oleh karena itu, praktik yoga yang dianjurkan adalah yang selain bermanfaat untuk mengatasi ketidaknyamanan fisik, juga yang bermanfaat untuk mengatasi tingkat kecemasan (Potter, 2010).

Praktik yoga yang disarankan adalah yang menciptakan "ruang" bagi ibu dan janin untuk tetap dapat bernapas dengan nyaman, melatih otot dasar panggul agar lebih elastis dan kuat, serta melakukan postur-postur restoratif dan relaksasi. Teknik olah napas yang diberikan perlakuan sedari awal masa kehamilan akan mambantu ibu lebih mudah memusatkan pikiran saat bermeditasi yang akan sangat berguna untuk menguatkan mental, mengatasi tingkat kecemasan, dan menghemat energi pada detik-detik persalinan kelak (Potter, 2010).

Hasil yang didapatkan setelah diberikan perlakuan yoga prenatal, yaitu ibu mengalami penurunan tingkat kecemasan, hal ini ditunjukkan dengan data penelitian bahwa 3 responden tidak mengalami kecemasan. Namun responden yang mengalami kecemasan ringan dan sedang datanya mendominasi. Hal ini sangat dipengaruhi oleh beberapa faktor diantaranya keadaan sekitar pada saat intervensi sehingga membuat ibu tidak bisa fokus dan tidak bisa rileks, serta keadaan lingkungan sekitar rumah. Hal ini sesuai dengan penelitian Jennifer tahun 2012 bahwa yoga dapat menurunkan tingkat kecemasan serta menekan beberapa gejala vegetatif tingkat kecemasan.
Hasil penelitian sebelumnya yang dilakukan oleh Jennifer (2012), setelah dilakukan yoga prenatal tingkat kecemasan ibu cenderung menurun, yaitu sebesar $40 \%$. Dari 10 responden yang mengalami kecemasan, 6 responden tidak mengalami cemas. Hal ini berkaitan dengan rutinitas ibu hamil dalam melaksanakan yoga, serta beberapa asanas yoga yang bisa membuat ibu hamil lebih merasa relaks (Sindhu, 2014).

Tabel 3 Perbedaan Tingkat Kecemasan Responden Sebelum dan Sesudah Diberikan Perlakuan Prenatal Yoga

\begin{tabular}{llll}
\hline & N & Mean & Nilai $\mathbf{p}$ \\
\hline Nilai Pre Test & 24 & 24,92 & \\
Nilai Post & 24 & 13,62 & 0,001 \\
Test & & & \\
\hline
\end{tabular}

Data pada tabel 3, hasil analisa menunjukkan ada perbedaan tingkat kecemasan responden sebelum dan sesudah diberikan perlakuan prenatal yoga dengan nilai $p$ value $=0,000$. Hipotesis nol ditolak karena $p<0,05$. Perbedaan tingkat tingkat kecemasan ditunjukkan dengan ratarata nilai tingkat kecemasan sebelum perlakuan yaitu 24,92 . Pengukuran rata-rata nilai post test yaitu 13,62. Terdapat penurunan nilai mean/rata-rata tingkat kecemasan sebesar 11,3. Tingkat kecemasan sedang menurun 16,7\%, dan tingkat kecemasan berat menurun 100\%. Hal ini sesuai dengan yang disampaikan Sindhu (2014) menjelaskan bahwa prenatal yoga memberikan pengaruh terhadap penurunan tingkat kecemasan.

Terjadi penurunan tingkat kecemasan secara statistik menunjukkan bahwa yoga mampu menurunkan tingkat kecemasan ibu hamil. Sesudah diberikan prenatal yoga ternyata tingkat kecemasan ibu lebih baik dibandingkan sebelumnya. Ibu hamil juga tetap memerlukan latihan fisik yang cukup yang akan membantu mencapai kesehatan yang optimal di sepanjang kehamilan dan stamina yang prima untuk menghadapi persalinan. Berlatih yoga selain bermanfaat untuk mengolah fisik juga bermanfaat untuk mengolah pikiran dan hati agar ibu hamil senantiasa merasa tenang dan tentram selain itu juga meningkatkan kemampuan 
ibu hamil untuk memusatkan perhatiannya agar dapat berkontemplasi dan berkomunikasi dengan bayinya. Hal ini sesuai dengan penelitian Jennifer (2012) bahwa yoga merupakan alternatif perlakuan untuk ibu hamil yang mengalami tingkat kecemasan. Yoga tidak hanya menurunkan tingkat kecemasan, namun juga menekan beberapa gejala vegetatif timbulnya tingkat kecemasan. Dalam penelitian tersebut disampaikan bahwa dari 10 responden yang mengalami kecemasan, setelah diberikan perlakuan prenatal yoga 6 responden tidak mengalami kecemasan. Artinya dalam penelitian tersebut, senam hamil mampu menurunkan tingkat kecemasan sebesar 40\% (Rahma, 2014)

Analisis peneliti, untuk gerakan yoga yang diberikan kepada ibu hamil sudah disesuaikan berdasarkan trimesternya, rangkaian gerakan yoga yang sudah dimodifikasi ini bila dilakukan secara teratur sepanjang kehamilan dapat mengkondisikan fisik dan mental untuk menjadi lebih kuat, kukuh tapi luwes dan fleksibel untuk menyesuaikan diri terhadap berbagai situasi yang tidak menyenangkan saat menghadapi persalinan. Beberapa gerakan yang mengarah dalam menurunkan kecemasan diantaranya yaitu pada setiap awal pertemuan, selalu dilaksanakan refocusing. Kemudian melakukan pemanasan, latihan pernafasan, gerakan Prasarita Padottanasana, Viparita Karani. Selanjutnya di akhir pertemuan selalu dilakukan teknik relaksasi.

Prenatal yoga merupakan alternatif olah raga yang disarankan bagi ibu hamil. Dilihat dari berbagai manfaatnya bagi fisik, mental, dan spiritual. Yoga prenatal merupakan yoga klasik yang sudah dimodifikasi untuk ibu hamil dengan memperhatikan gerakangerakan yang tidak berbahaya baik bagi ibu dan janin. Di wilayah kerja Puskesmas I Kembaran, sebelumnya belum pernah dilakukan prenatal yoga. Sehingga peneliti berusaha memasyarakatkan prenatal yoga di kalangan ibu hamil.

\section{Simpulan dan Saran}

Simpulan penelitian ini yaitu ada pengaruh prenatal yoga terhadap tingkat kecemasan primigravida trimester III, dimana prenatal yoga mampu menurunkan tingkat kecemasan (terdapat perubahan mean sebesar 11,3). Saran kepada ibu hamil untuk berlatih prenatal yoga secara rutin di rumah guna mempersiapkan kehamilan yang sehat baik fisik mamupun mental

\section{Ucapan terima kasih}

Terima kasih peneliti ucapkan kepada Poltekkes Kemenkes Semarang atas kesempatannya sehingga peneliti mendapatkan dana Risbinakes DIPA Poltekkes Kemenkes Semarang, Kepala Puskesmas I Kembaran, Bidan Desa Kembaran dan seluruh pihak yang membantu proses penelitian ini yang tidak bisa kami sebutkan satu persatu

\section{Daftar Pustaka}

Evan J. Managing Perinatal Psychiatric Problem. Journal of pediatric, Obstetric and Gynocologic November-Desember. 2002.

Field T, Diego M, Medina L, Delgado J, Hernandez A. Yoga and massage therapy reduce prenatal depression and prematurity. NIH Public Access. April; 2012; 16(2):204-209.

Kathryn Curtis, Aliza Weinrib, Joel Katz. Systematic Review of Yoga for Pregnant Women : current status and future direction. 2012.

Kusmiyati, dkk. Perawatan lbu Hamil. Yogyakarta: Fitramaya. 2009; 15.

Kuswandi, Lanny. Keajaiban Hypnobirthing. Jakarta: Pustaka Bunda. 2002; 29-31.

Potter, Perry. Fundamental Keperawatan Buku 2 Edisi 7. Jakarta : Salemba Medika. 2010.

Pusdiknakes. Panduan Pengajaran Asuhan Kebidanan Fisiologis Bagi Dosen Diploma III Kebidanan; Buku 2 Asuhan Antenatal. Jakarta: Pusdiknakes. 2003; 27-28:74-88.

Rahma, F. Hubungan senam yoga terhadap peningkatan kualitas tidur ibu hamil trimester III. Universitas Muhammadiyah Surakarta. Diperoleh 20/05/2018 melalui http://prints.ums.ac.id/30487/10/NASKA H PUBLIKASI.pdf.2014

Sindhu, Pujiastuti. Yoga Untuk Kehamilan edisi yang diperkaya; sehat, bahagia 
dan penuh makna. Bandung: Qanita. 2014

Suririnah. Stres dalam kehamilan berpengaruh buruk. Di unduh dari: http://www.infoibu.com/mod.php?mod=publi sher\&op=viewarticle\%artid=27 (Di akses 19 September, 2013), 2004 